\title{
Molecular genetic tests as a guide to surgical management of familial adenomatous polyposis
}

\author{
H F A Vasen, $R$ B van der Luijt, J F M Slors, E Buskens, P de Ruiter, C G M Baeten, W R Schouten, H J M Oostvogel,
} J H C Kuijpers, C M J Tops, P Meera Khan

\begin{abstract}
Summary
Background In familial adenomatous polyposis the only curative treatment is colectomy, and the choice of operation lies between restorative proctocolectomy (RPC) and colectomy with ileorectal anastomosis (IRA). The RPC procedure carries a higher morbidity but, unlike IRA, removes the risk of subsequent rectal cancer. Since the course of familial adenomatous polyposis is influenced by the site of mutation in the polyposis gene, DNA analysis might be helpful in treatment decisions.
\end{abstract}

Methods We evaluated the incidence of rectal cancer in polyposis patients who had undergone IRA, and examined whether the requirement for subsequent rectal excision because of cancer or uncontrollable polyps was related to the site of mutation.

Findings Between 1956 and mid-1995, 225 patients registered at the Netherlands Polyposis Registry had undergone IRA. In 87 of them, a pathogenetic mutation was detected. 72 patients had a mutation located before codon 1250 and 15 patients after this codon. The cumulative risk of rectal cancer 20 years after surgery was $12 \%$, and at that time $42 \%$ had undergone rectal excision. The risk of secondary surgery was higher in patients with mutations in the region after codon 1250 than in patients with mutations before this codon (relative risk 2.7, $p<0.05$ ).

Interpretation On this evidence, IRA should be the primary treatment for polyposis in patients with mutations before codon 1250, and RPC in those with mutations after this codon.

Lancet 1996; 348: 433-35

See Commentary page 422

The Netherlands Foundation for the Detection of Hereditary Tumours, Leiden, and Department of Gastroenterology, Leiden University Hospital, Leiden, Netherlands (H F A Vasen MD); M GC-Department of Human Genetics, Leiden University, Leiden ( $R$ B van der Luijt PhD, C M J Tops PhD, Prof P Meera Khan MD); Department of Surgery, Academic Medical Centre, Amsterdam (J F M Slors MD); Department of Clinical Epidemiology, Utrecht University Hospital, Utrecht (E Buskens MD); Department of Surgery, Medical Centre, Alkmaar (P de Ruiter MD); Department of Surgery, Maastricht University Hospital, Maastricht (C G M Baeten MD); Department of Surgery, Rotterdam University Hospital Dijkzigt, Rotterdam (W R Schouten MD); Department of Surgery, St Elisabeth Hospital, Tilburg (H J M Oostvogel MD); and Department of Surgery, Nijmegen University Hospital, Nijmegen (J H C Kuijpers MD)

Correspondence to: Dr H F A Vasen, The Netherlands Foundation for the Detection of Hereditary Tumours, University Hospital,

Rijnsburgerweg 10, Building no 50, 2333 AA Leiden, Netherlands

\section{Introduction}

Familial adenomatous polyposis (FAP) or BusseyGardner polyposis ${ }^{1}$ is an autosomal dominant disease characterised by hundreds of adenomas in the colon and by various extracolonic features. ${ }^{2} \mathrm{~T}$ he disease is due to a mutation in the adenomatous polyposis coli (APC) gene which is located on chromosome 5.,4 The APC gene consists of 15 coding exons and probably influences interactions between cells. M ost patients develop adenomatous polyps in their colon in the second and third decade of life ${ }^{2}$ and if untreated they get colorectal cancer in their thirties. We now know that individuals with identical mutations can show differences in phenotypic expression of the disease; ${ }^{5,6}$ nevertheless, several investigators report correlations between mutations occurring within specific regions of $A P C$ and the phenotypic expression. M utations within exons 3 and 4 are associated with a less severe form of FAP characterised by a low number of colorectal adenomas and a late age of onset of colorectal cancer. ${ }^{7} \mathrm{Nagase}^{8}$ reports that patients with mutations located in a region between codons 1250 and 1464 at exon 15 tend to have more than 5000 adenomatous polyps and to develop colorectal cancer at an average age of 34 . Whereas those with mutations outside this region have fewer than 2000 polyps and develop colorectal cancer at 41.8 years. A severe form of FAP has been associated with a deletion in codon $1309^{\circ}$ and with mutations after codon $1250 .{ }^{10,11}$

$M$ ight information on the location of the mutation be useful in determining the most appropriate surgical treatment? There has been a long debate about the extent of colonic surgery. If the rectum is carpeted with polyps or if the patient is unlikely to attend regularly for followup, there is a good case for restorative proctocolectomy (RPC). If the rectum is relatively free of adenomas, colectomy with ileorectal anastomosis (IRA) is the most attractive surgical procedure because of its satisfactory functional results. A drawback of IRA, however, is the substantial risk of cancer in the residual rectum; ${ }^{12,13}$ moreover, a high proportion of the patients need rectal excision because of uncontrollable polyps. In the present study, we evaluated the cumulative risk of rectal cancer in a large series of patients in the $\mathrm{N}$ etherlands. We also assessed the rate of rectal excision after IRA and whether the probability of secondary surgery is associated with the location of the mutation.

\section{Methods}

In 1985 a registry of families with familial adenomatous polyposis was set up in the $\mathrm{N}$ etherlands, ${ }^{14}$ and by July 1,1995 , genealogical studies had been performed in 200 families with FAP referred from all parts of the country. $M$ edical and pathological data were collected to verify the family history. Data collection was complete in 150 of the 200 families and these families were selected for the present study.

Between 1956 and mid-1995, 230 patients had IRA performed as a primary procedure for polyposis and 81 
underwent RPC. In all cases the diagnosis of FAP was confirmed by the presence of more than 100 adenomatous polyps and/or the identification of a mutated APC gene. The surgical operations were done in hospitals all over the $\mathrm{N}$ etherlands. Before 1990, in most centres, the preferred treatment of polyposis patients with few rectal polyps was IRA.

For risk assessment, patients who had an IRA were studied with respect to their risk of developing rectal cancer or requiring excision of the rectum. The data were analysed by survival analysis methods. Observation time was up to the date of last contact, death, the date of diagnosis of rectal cancer, the date of rectal excision, or the closing date of the study. Differences in risk of undergoing rectal excision were tested for statistical significance by the log rank test. M utation studies of the APC gene conducted in the families registered at the Dutch Polyposis Registry have been described elsewhere. ${ }^{15,16}$

\section{Results}

Of the 230 patients who had an IRA, 5 had follow-up of less than one year after surgery and were excluded. The remaining 225 had a mean follow-up of $11 \mathrm{yr}$ (range 1-38). M ean age at surgery was $28.3 \mathrm{yr}$ (range 11-70). 16 of these patients developed a rectal cancer (mean age 45 $\mathrm{yr}$; range 29-61). Of these 16 patients, information on screening was available in 12: 11 had undergone surveillance within the previous 12 months. The interval since the last endoscopic examination ranged from 3 to 14 months (mean 8.8 months). Figure 1 shows the cumulative risk of developing rectal cancer by years of follow-up after surgery. At 10, 15, 20, and 25 years after surgery the cumulative risks were $3.9 \%$ (95\% confidence interval $0.9-6 \cdot 8 \%), \quad 10.4 \% \quad(4.5-16.3 \%), \quad 12 \cdot 1 \%$ $(5 \cdot 4-18 \cdot 8 \%)$, and $25 \cdot 8 \%(6 \cdot 6-45 \cdot 1 \%)$. Seven of the 16 rectal cancer patients died, six from the cancer and one from postoperative complications. In 45 of the 225 patients the rectum had to be removed because of recurrent polyps ( $n=29$, mean age: $33 \mathrm{yr}$ ) or rectal cancer $(n=16)$. The cumulative risk of rectal excision 10,15 , and 20 years after IRA was $15.0 \%(95 \% \mathrm{Cl} 9 \cdot 6-20 \cdot 3 \%)$, $32 \cdot 2 \%(23 \cdot 9-40 \cdot 6 \%)$, and $42 \cdot 2 \%(30 \cdot 0-54 \cdot 4 \%)$.

\section{Mutation analysis}

DNA analysis was conducted in 105 of the 150 polyposis families and the pathogenic mutation was detected in 56 families. 32 of these families had at least one member who underwent an IRA. 21 families including 72 patients with an IRA (group A) had a mutation before codon 1250 and the remaining 11 families including 15 individuals with an IRA (group B) had a mutation after this codon. 14 of the patients from group $A$ and eight of the patients from group $B$ required rectal excision because of rectal cancer of uncontrollable polyps. The cumulative risk of rectal excision by years of follow-up after surgery was significantly higher in group $B$ than in group $A$ (relative risk $2 \cdot 7$; log rank test $p<0.05$ ) (figure 2 ).

\section{Discussion}

Although non-steroidal anti-inflammatory drugs may have some beneficial effect on colonic adenomas, ${ }^{17}$ prophylactic surgery of the colon is still the only curative treatment for polyposis. Restorative proctocolectomy might seem the ideal operation. By removal of all or nearly all the large-bowel mucosa the risk of cancer can be almost completely avoided. There are disadvantages, however, and the most important are the greater morbidity and duration of convalescence than with IRA and the possible failure of the pouch-a complication that

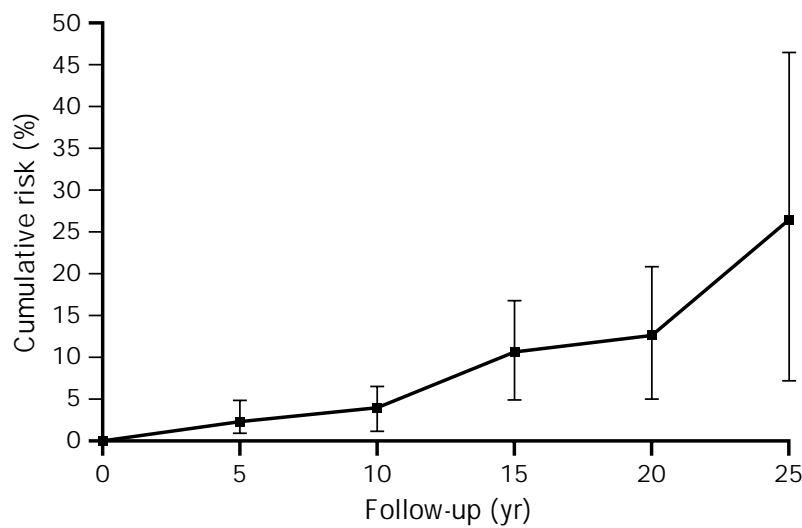

Figure 1: Cumulative risk of rectal cancer after ileorectal anastomosis over 25 years of follow-up Bars are $95 \%$ confidence intervals.

requires an ileostomy. Because most of the FAP patients who need surgery are between 15 and 25 years of age, such a procedure would seriously interfere with their education and the development of social relationships. Selection of patients for IRA or RPC must therefore depend on the balance of pros and cons-the morbidity and the possible failure of RPC versus the risk of cancer in the remaining rectum after IRA. Several reports from the 1980s indicated that the risk of rectal cancer gradually increases with time and amounts to $10-55 \%$ after 20 years of follow-up. ${ }^{12,13}$ O ne recent large-scale study from the Scandinavian countries covering 294 patients indicated a rectal cancer risk of $9 \%$ and $13 \%$ after 20 and 25 years of follow-up, respectively. ${ }^{18}$ These data are in agreement with the results of the St M ark's Polyposis Registry. ${ }^{13}$ The present study, which covered a comparable number of patients, yielded about the same risk at 20 years of follow-up. A Japanese study comprising 320 patients showed a much higher risk, 37\% after 20 years. ${ }^{19}$ An update of the St M ark's series reveals that the risk of rectal cancer increases sharply after the age of 50 years and is as high as $29 \%$ at age $60 .^{20}$

Possible explanations for the discrepancies in incidence of rectal carcinoma between centres may include differences in the length of the rectal stump, the age at colectomy, and the quality of follow-up after surgery. In addition, variation in the definition of "uncontrollable" polyps between centres may contribute to the differences in rectal carcinoma incidence. The confidence intervals for the risks reported for a follow-up of 20 years or longer

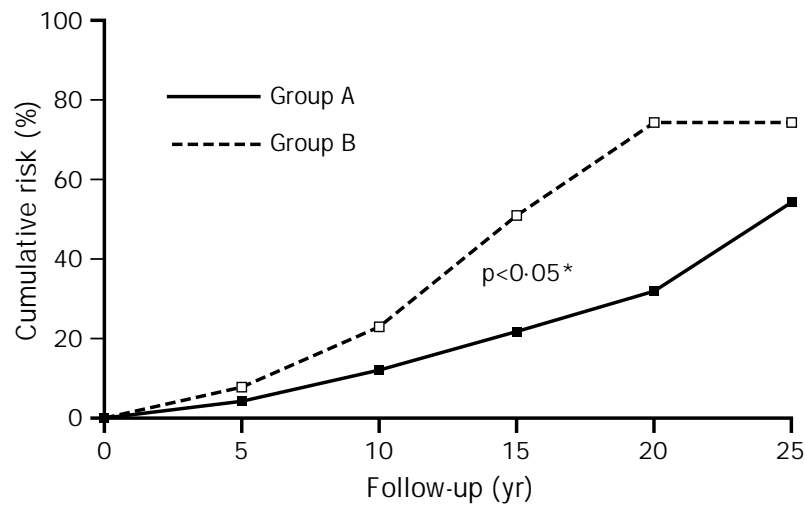

Figure 2: Cumulative risk of rectal excision by years of follow-up after surgery in patients with mutations before codon 1250 (group A) and downstream from codon 1250 (group B)

* Log rank test. 
are very wide in most series (because of the small number of patients with such a long follow-up) and, in fact, the differences between the studies may fall within these limits. Could the rectal cancers have been prevented by regular rectoscopy? Almost all the patients with rectal cancer in the present series were under close surveillance and the interval since the last examination had been less than one year. The St M ark's experience also indicated that the patients who developed rectal cancer were good compliers and most had undergone surveillance within the past six months. ${ }^{20}$

The risk of rectal cancer is not the only factor in the choice of operation. An important consideration is the likelihood that, after IRA, a patient will later require rectal excision. In our series, 20 years after IRA almost half the patients had needed rectal excision for rectal cancer or for polyps that could not be controlled by polypectomy. If we were able to identify the patients who would need secondary surgery after IRA, such patients could be selected for a more definitive primary surgical procedure (RPC). Several studies have shown that the course of the disease in families with polyposis due to a mutation in the region after codon 1250 on exon 15, especially at codon 1309 , tends to be more aggressive than in families with mutations before this codon. ${ }^{8-11}$ Patients from such families may be at greater risk of recurrent polyps and rectal cancer after IRA. To test this hypothesis we evaluated the cumulative risk of rectal excision in a subgroup of patients with a known mutation. We found that the risk of rectal excision in patients with a mutation after 1250 is indeed higher than that in patients with a mutation before this codon.

We conclude that the results of DNA testing in relation to the phenotypic expression in the patient and family could be helpful in surgical decision-making. In patients with a mutation in the region after codon 1250, who are at high risk of rectal excision after IRA, RPC is the treatment of choice; whereas in patients with a mutation before codon 1250 colectomy and IRA is the preferred treatment.

We thank I S J van L eeuwen-C ornelisse for collecting the family material, $M E$ J G errits and M E Velthuizen for assembling the clinical information and maintaining the data-bases, and I Seeger-Wolf for reviewing the English text.

\section{References}

1 Spigelman AD, Thomson JPS, Philips RK S. N omenclature: familial adenomatous polyposis (Bussey-G ardner polyposis). In: Philips RKS, Spigelman AD, Thomson JPS, eds. F amilial adenomatous polyposis. London: Edward Arnold, 1994.

2 Bussey HJR. Familial polyposis coli. Baltimore: Johns H opkins U niversity Press, 1975.

3 K inzler K W, N iblert M C, Su L-K, et al. Identification of FAP locus gene from chromosome 5q21. Science 1991; 253: 661-69.

4 Groden J, Thliveris A, Samowitz W, et al. Identification and characterization of the familial adenomatous polyposis coli gene. Cell 1991; 66: 589-600.

5 Paul P, L etteboer T, G elbert $L$, et al. I dentical APC exon 15 mutations result in a variable phenotype in familial adenomatous polyposis. $\mathrm{H}$ um M olec G enet 1992; 2: 925-31.

6 Giardello FM , K rush AJ, Petersen GM , et al. Phenotypic variability of familial adenomatous polyposis in 11 unrelated families with identical APC gene mutation. Gastroenterology 1994; 106: 1542-47.

7 Spirio L, Olschwang S, G roden J, et al. Alleles of the APC gene: an attenuated form of familial polyposis. Cell 1993; 75: 951-57.

$8 \mathrm{~N}$ agase $\mathrm{H}, \mathrm{M}$ iyoshi $\mathrm{Y}, \mathrm{H}$ orii $\mathrm{A}$, et al. Correlation between the location of germ-line mutations in the APC gene and the number of colorectal polyps in familial adenomatous polyposis patients. Cancer R es 1992; 52: 4055-57.

9 Caspari R, Friedl W, M andl M , et al. Familial adenomatous polyposis: mutation at codon 1309 and early onset of colon cancer. L ancet 1994; 343: $629-32$.

10 G ayther SA, W ells D, Sengupta SB, et al. Regionally clustered APC mutations are associated with a severe phenotype and occur at high frequency in new mutation cases of adenomatous polyposis coli. $\mathrm{H}$ um M ol G enet 1994; 3: 53-56.

$11 \mathrm{~N}$ ugent K P, Philips RK S, H odgson SV, et al. Phenotypic expression of familial adenomatous polyposis: partial prediction by mutation analysis. G ut 1994; 35: 1622-23.

12 Bess M A, Adson M A, Elveback LR, et al. Rectal cancer following colectomy for polyposis. A rch Surg 1980; 115: 460-67.

13 Bussey HJ, Eyers AA, Ritchie SM, et al. The rectum in adenomatous polyposis: the St M ark's policy. Br J Surg 1985; 72: S29-31.

14 Vasen HFA, G riffioen G, Offerhaus GJA, et al. The value of screening and central registration of families with familial adenomatous polyposis. A study of 82 families in the $N$ etherlands. D is C olon R ectum 1990; 33: 227-30.

15 Fodde R, Van der L uyt R, Wijnen J, et al. Eight novel inactivating germ line mutations at the APC gene identified by denaturing gradient gel electrophoresis. G enomics 1992; 13: 1162-68.

16 Van der L uyt R, M eer $K$ han $P, V$ asen $H$, et al. Rapid detection of translation-terminating mutations at the adenomatous polyposis coli (APC) gene by direct protein truncation test. G enomics 1994; 20: $1-14$.

17 L abayle D, F ischer D, Vielh $P$, et al. Sulindac causes regression of rectal polyps in familial adenomatous polyposis. G astroenterology 1991; 101: $635-39$.

18 D ecosse JJ, Bülow S, N eale K, et al. Rectal cancer risk in patients treated for familial adenomatous polyposis. B I S Surg 1982; 79: 1372-75.

19 I wama T, M ishima Y, U tsunomiya J, et al. The impact of familial adenomatous polyposis on the tumorigenesis and mortality at several organs. A nn Surg 1993; 217: 101-18.

20 N ugent KP, Philips RK S. Rectal cancer risk in older patients with familial adenomatous polyposis and an ileorectal anastomosis: a cause for concern. Br J Surg 1992; 79: 1204-06. 